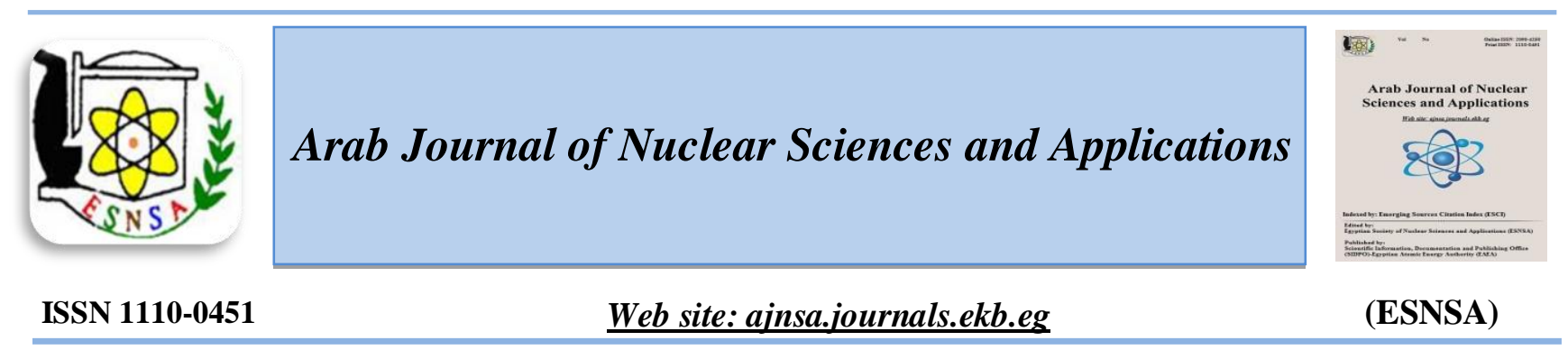

\title{
On the Question of Spin Assignment and Quantized Alignment in the A 100- 140 Superdeformed Mass Region
}

\author{
A.S. Shalaby \\ Physics Department, Faculty of Science, Beni-Suef University, Egypt
}

Received $1^{\text {st }}$ Nov. 2018 The structure of the superdeformed (SD) mass region, A 100-140 is re-studied using a direct approach Accepted $17^{\text {th }}$ Apr. 2019 based on the rotational energy formula $E(I, K)$. The variation of the kinematic $\theta^{(1)}$ and dynamic $\theta^{(2)}$ moments of inertia as a function of rotational frequency $(\hbar \omega)$ have been examined to calculate the lowest spin $\left(I_{f}\right)$ and the $K$-value of the $S D$ bands: ${ }^{104} \mathrm{Pd}(b 1),{ }^{132} \mathrm{Ce}(\mathrm{b} 1),{ }^{134} \mathrm{Nd}(\mathrm{b} 1),{ }^{136} \mathrm{Nd}(\mathrm{b2}),{ }^{142} \mathrm{Sm}(\mathrm{b} 1),{ }^{148} \mathrm{Eu}(\mathrm{b} 1$, b2), ${ }^{131} \mathrm{Ce}(\mathrm{b} 1, \mathrm{b2}),{ }^{133} \mathrm{Ce}(\mathrm{b} 1, \mathrm{b2}),{ }^{133} \mathrm{Pr}(\mathrm{b} 1, \mathrm{b3}),{ }^{137} \mathrm{Sm}(\mathrm{b} 1)$ and ${ }^{143} \mathrm{Eu}(\mathrm{b} 1)$. The expansion parameters $\mathrm{A}$ and $B$, of such method have been adjusted using a search program to fit the proposed transition energies $\mathbf{z}$ with their corresponding experimental ones. The calculated E $\gamma$ are strongly dependent on the identified spins. It was found that, when an accurate bandhead spin $\left(I_{0}\right)$ is assigned, a good agreement is achieved between the calculated $E \gamma$ and their corresponding experimental data. The results for the spin are in satisfactory agreement with other theoretical results and available experimental data. The good agreement between the calculation and experiment gives good support to the model set. The incremental alignment $\Delta i$ and also the angular momentum alignment $i(\omega)$, for the identical SD bands (ISDB's) exist among the considered ones, have been studied and the results verified well Stephens's law of alignment.

\section{Introduction}

Keywords: Superdeformed nuclei, Mass Region 100-140, Spin alignment
Since the experimental discovery of the first superdeformed band (SD) in a fast-rotating nucleus ${ }^{152}$ Dy [1, 2], a large number of super deformed bands have been observed in the mass regions A 190, 150, 130 [3, 4], 80 [4-6] and 60 [7]. The super deformation in the mass region A 100-140 is specially of great interest [8-18] due to the poor study of these SD nuclei theoretically. The broad feature of this SD mass region is that, for most of its bands, the dynamic moment of inertia $\Theta^{(2)}$ exhibits a smooth decrease as the rotational frequency $\hbar \omega$ increases.

Unfortunately, the only available spectroscopic information for SD bands is $\gamma$-ray transition energies $[19,20]$. This is due to the difficulties in observing discrete transitions linking the SD levels and the normal deformed (ND) ones [19]. The value of the spin can only be calculated theoretically because of the insufficient and poor availability of experimental data for the spin of the rotational bands. Several methods have been proposed [21-36] to determine the spins of SD bands. These methods are classified into direct and indirect approaches for determining the spin of SD bands.

In the present work, a simple model which belongs to the direct approaches is used where the rotational energy, $\mathrm{E}_{\text {rot }}(\mathrm{I}, \mathrm{K})$, depends upon the spin, I, and the projection of the angular momentum along the symmetry axis, $\mathrm{K}$.

The extremely close coincidence in the $\gamma$-ray transitions between certain pairs of bands in different nuclei [37] leads to the discovery of the identical bands (IB's) phenomenon which may be characterized by incremental and spin alignments [38-40].

The properties of the SD mass region 190 have been studied via the IB's phenomenon by Stephens

Corresponding author: ashalaby15@yahoo.com

DOI: 10.21608 /ajnsa.2019.6023.1133

(C) Scientific Information, Documentation and Publishing Office (SIDPO)-EAEA 
et al. $[39,40]$ and it was found that the alignment values lie between \pm 0.5 and it takes a value close to zero for approximately identical transition energies. Using the same procedures as that given by Stephens et al. [39], we will investigate the alignment between the nearly IB's appeared among the considered SD bands.

The aim of the present work is to calculate the lowest spin "I" " of fifteen SD bands in the mass region 100-140, the values of the incremental alignment and spin alignment for the IB's exist among the considered ones, to verify Stephens's law of alignment. Also, the success of this approach in some regions of the periodic table [3436] motivated us to prove its validity in another region of it.

Section 1 of this study is the above introduction, in section 2, the theoretical framework used to assign the lowest spin $\mathrm{I}_{\mathrm{f}}$ of the considered fifteen bands in the A 100-140 SD mass region is presented. It also gives the formulas required to determine the incremental and the spin alignments. The results and discussion of the data obtained by making use of such approach are given in section 3. The results for the spins of the considered SD bands are found to be satisfactorily good. The transition energies of these SD bands were calculated with the aid of the assigned spins and the results found to be quite good. The incremental and spin alignments of the ISDB's were analyzed and discussed in this section. Finally concluding remarks are presented in section 4 .

\section{Theoretical Framework}

In the current approach, the rotational energy $E_{\text {rot }}$ $(\mathrm{I}, \mathrm{K})$ is given in terms of the rotational angular momentum as follows [36, 41]:-

$$
E_{\text {rot }}(I, K)=\left(\hbar^{2} / 2 \phi\right)\left[I(I+1)-K^{2}\right]
$$

Where, $\phi$ is the moment of inertia.

This equation can be written more generally as a function of $\left[I(I+1)-K^{2}\right]$ as:-

$$
E_{\text {rot }}(I, K)=A\left[I(I+1)-K^{2}\right]+B\left[I(I+1)-K^{2}\right]^{2}+C\left[I(I+1)-K^{2}\right]^{3}+\ldots .
$$

Where $\mathrm{A}=\left(\hbar^{2} / 2 \phi\right), \mathrm{B}$ and $\mathrm{C}$ represents the higher order inertial parameters to be determined.

The total energy for SD band is given by [36]:-

$E_{S}(I, K)=E_{o}+E_{r o t}(I, K)$

Where " $E_{0}$ " is the bandhead energy of the suberdeformed band.
Using Eq. (3), the transition energy from level "I+2" to level "I" takes the form [36]:

$E_{\gamma}(I)=E_{S}(I+2 \rightarrow I)=A[4 I+6]+B\left[8 I^{3}+36 I^{2}+I\left(60-8 K^{2}\right)-12 K^{2}+36\right]+\ldots .$.

The expansion parameters $\mathrm{A}$ and $\mathrm{B}$ can be obtained by fitting Eq. (4) with the experimental $\gamma$ ray transitions:

$E_{\gamma}\left(I_{0}+2 n\right), E_{\gamma}\left(I_{0}+2 n-2\right), \ldots . . E_{\gamma}\left(I_{0}+4\right)$ and $E_{\gamma}\left(I_{0}+2\right)$

[36].

A successful determination of the K-value and/ or the spin of the SD band are the main goal of such approach because they calculate the energies of the considered SD bands. The angular momentum is also estimated for such considered SD mass region 100-140 in our previous papers [42, 43] using other theoretical approaches and the present results seem to be relatively good.

To ensure from the calculated spin $\left(\mathrm{I}_{0}\right)$ was another check done as follows:

if "I $\mathrm{I}_{0}$ " shifts away from the accurate value by \pm 1 , rapid shift can be observed in the root mean square (r.m.s.) deviation $(\sigma)$ which is given by $[25,43]$,

$\sigma=\left[\frac{1}{n} \sum_{i=1}^{n}\left|\frac{E_{\gamma}^{\text {cal. }}\left(I_{i}\right)-E_{\gamma}^{\text {exp. }}\left(I_{i}\right)}{E_{\gamma}^{\exp }\left(I_{i}\right)}\right|^{2}\right]^{1 / 2}$

Where " $\mathrm{n}$ " is the total number of $\gamma$-ray transitions included in the fitting. " $\sigma$ " as used before in previously published papers $[36,43]$ and by others $[25,44,45]$ was chosen to fit because the experimental error bars in determination of the level energies are used not reported in the literature $[25,44,45]$. The spin values of all 15 SD bands can be determined just once the value of the lowest spin "I $\mathrm{I}_{0}$ " is known. It is obvious that this fitting technique is quite easier and straightforward than that using Harris formula [31, 42].

In this work, the incremental alignment $\Delta \mathrm{i}$ and also the spin alignment $\mathrm{i}(\omega)$ are calculated by using the same expressions given in a previous work by the author [36] and another work [39], these are:-

$\Delta i=\frac{\Delta E_{\gamma}(\text { reference band })-\Delta E_{\gamma}(\text { considered band })}{\Delta E_{\gamma}^{(2)}(\text { reference band })-\Delta E_{\gamma}^{(1)}(\text { reference band })}$

$\Delta I=i($ considered band $)-i($ reference band $)$

$i(\omega)=\Delta i+\Delta I$

Where $\Delta \mathrm{i}, \Delta \mathrm{I}$ and $\mathrm{i}(\omega)$ are referred to the incremental alignment, spin differences and spin alignment, respectively.

Arab J. Nucl. Sci. \& Applic. Vol. 52, No. 3 (2019) 


\section{Results and Discussion}

Another feature of the SD mass region 100-140 is that $\Delta E_{\gamma}$ smoothly increases with spin I so both the kinematic $\theta^{(1)}$ and dynamic $\theta^{(2)}$ moments of inertia must decrease with spin I where $\theta^{(1)}$ in most cases must be greater than $\theta^{(2)}$. In order to assign the correct value of the lowest spin $\mathrm{I}_{\mathrm{f}}$ or $\mathrm{K}$ value, $\theta^{(1)}$ and $\theta^{(2)}$ are plotted against $\hbar \omega$, for various values of prescribed spin. The results are shown in Figs. (1-15), where the assigned value of the lowest spin is represented by an open circle.

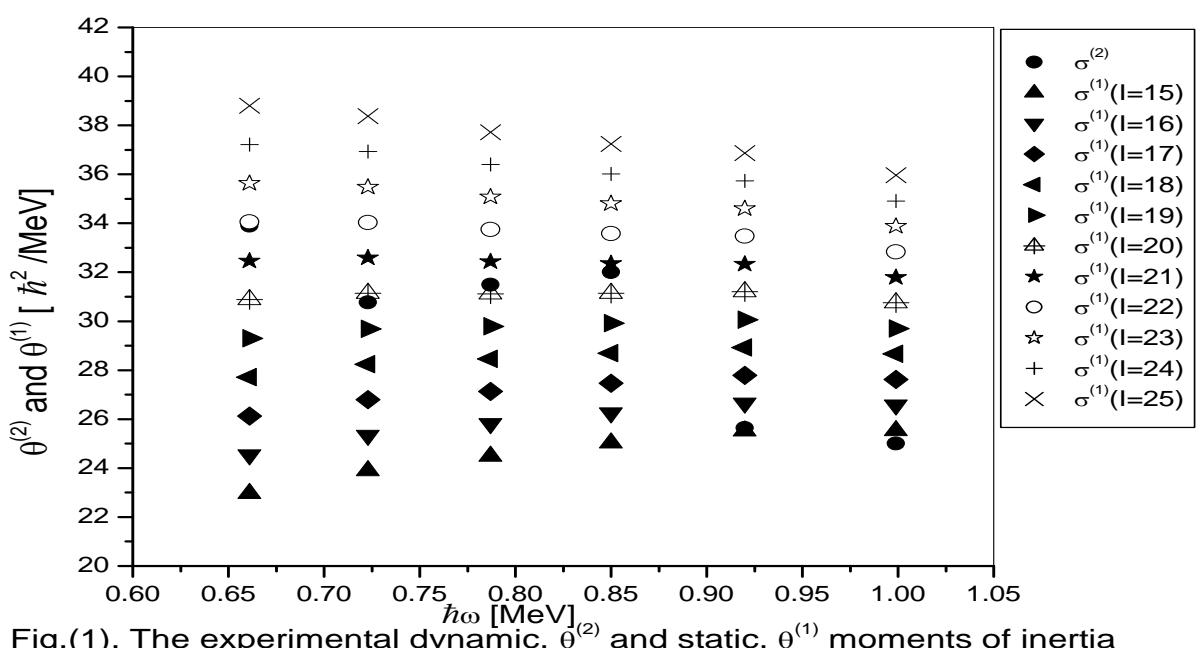

Fig.(1). The experimental dynamic, $\theta^{(2)}$ and static, $\theta^{(1)}$ moments of inertia versus rotational frequency, $\hbar \omega$ for the SD nucleus ${ }^{104} \mathrm{Pd}(\mathrm{b} 1)$.

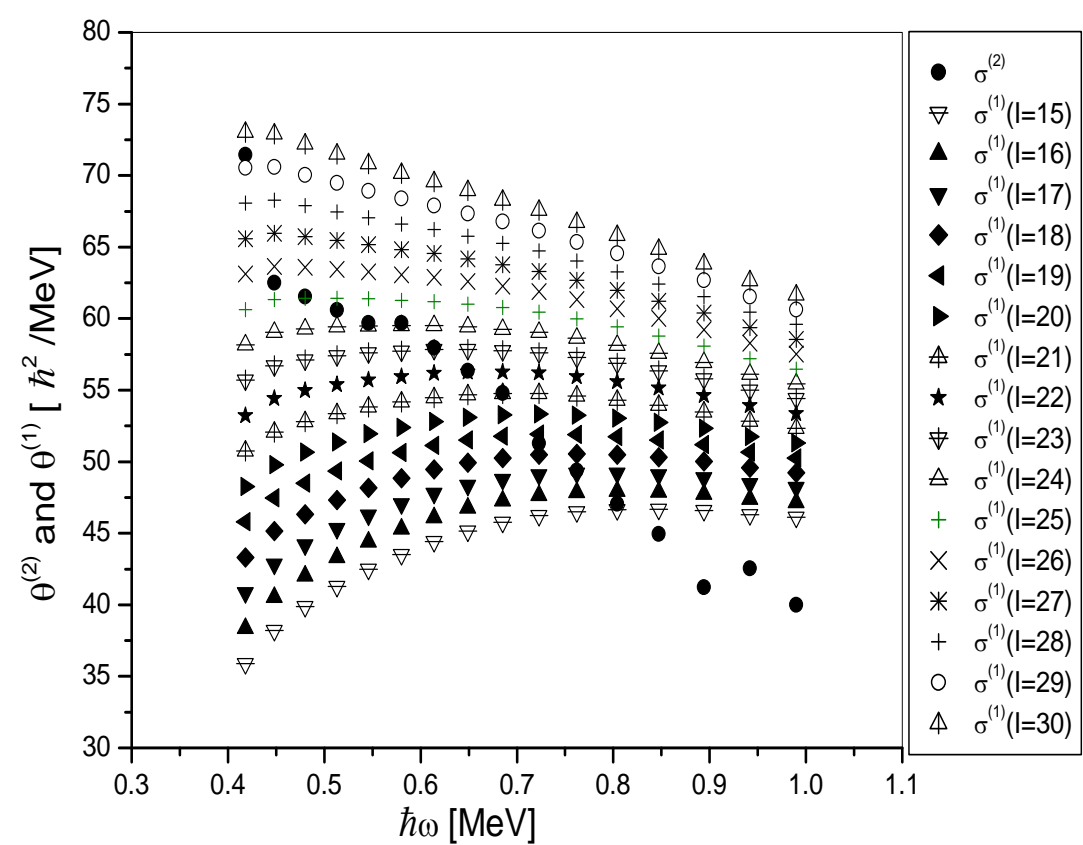

Fig.(2). The same as Fig. (1), but for for the SD nucleus ${ }^{132} \mathrm{Ce}(\mathrm{b} 1)$. 


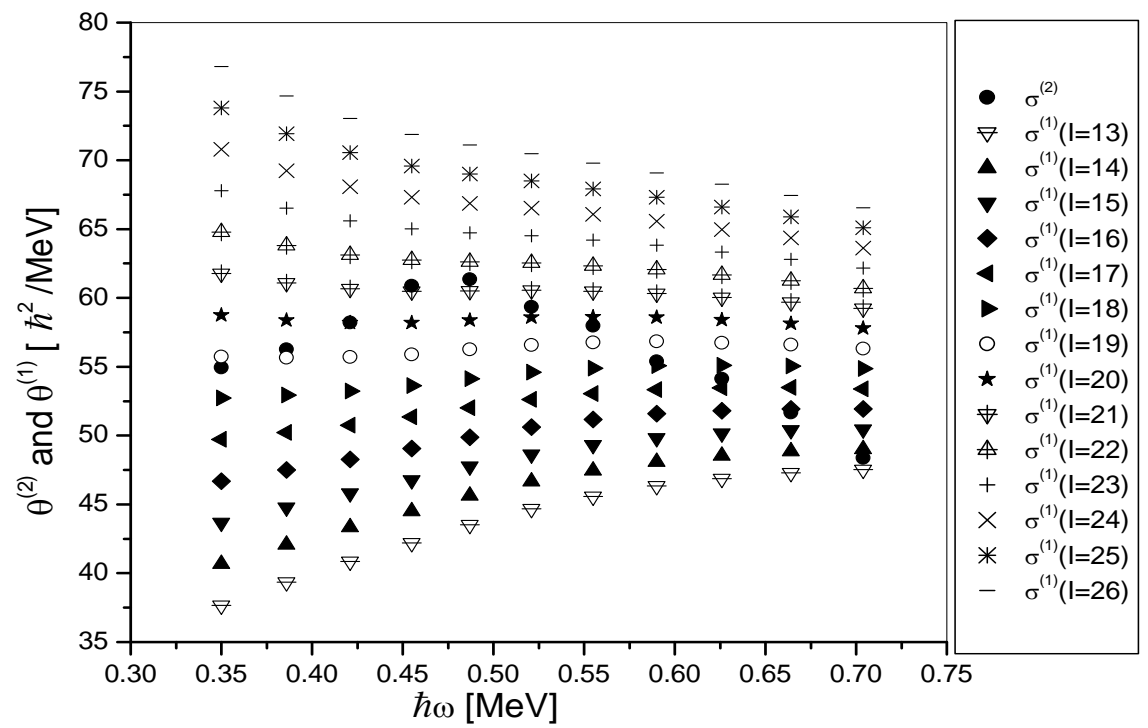

Fig.(3). The same as Fig. (1), but for the SD nucleus ${ }^{134} \mathrm{Nd}(\mathrm{b} 1)$.

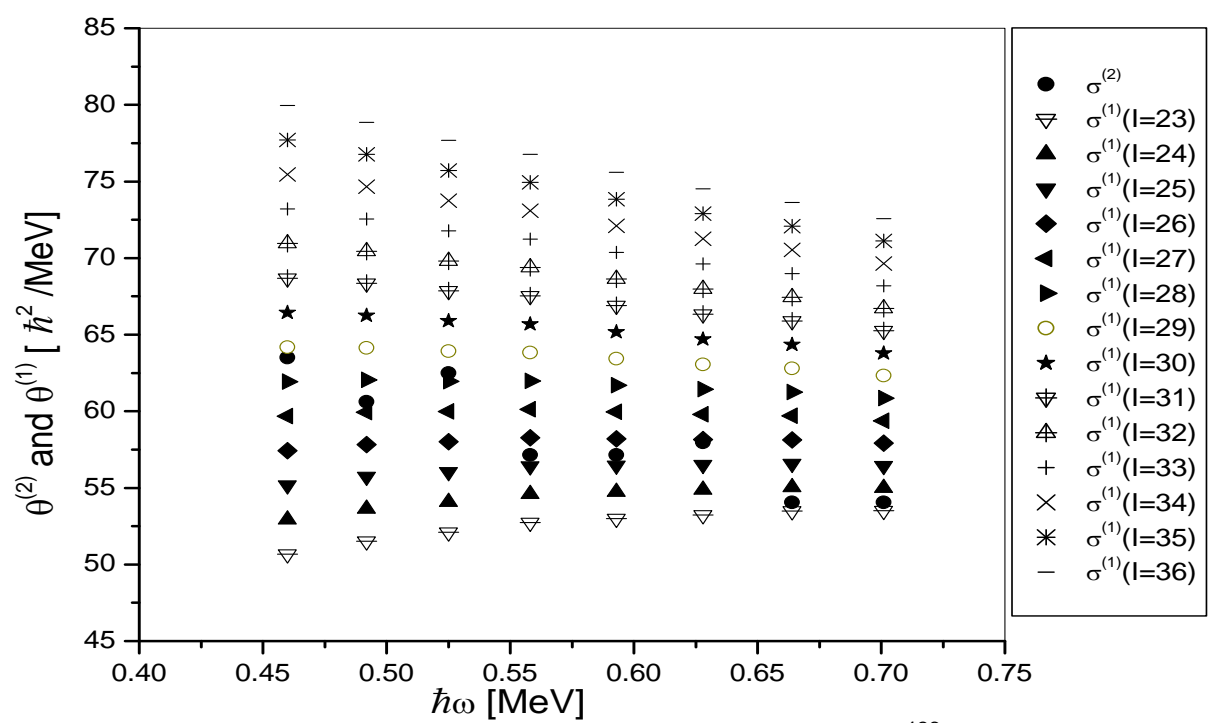

Fig.(4). The same as Fig. (1), but for the SD nucleus ${ }^{136} \mathrm{Nd}(\mathrm{b} 2)$. 


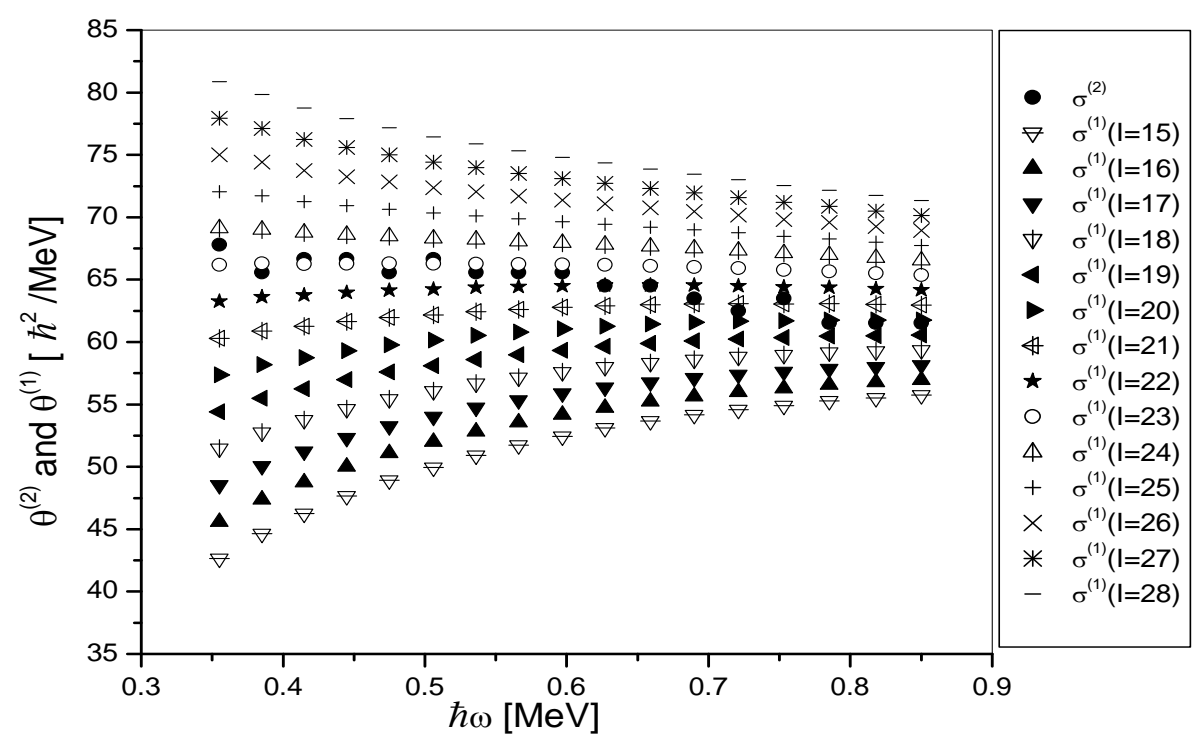

Fig.(5). The same as Fig. (1), but for the SD nucleus ${ }^{142} \mathrm{Sm}(\mathrm{b} 1)$.

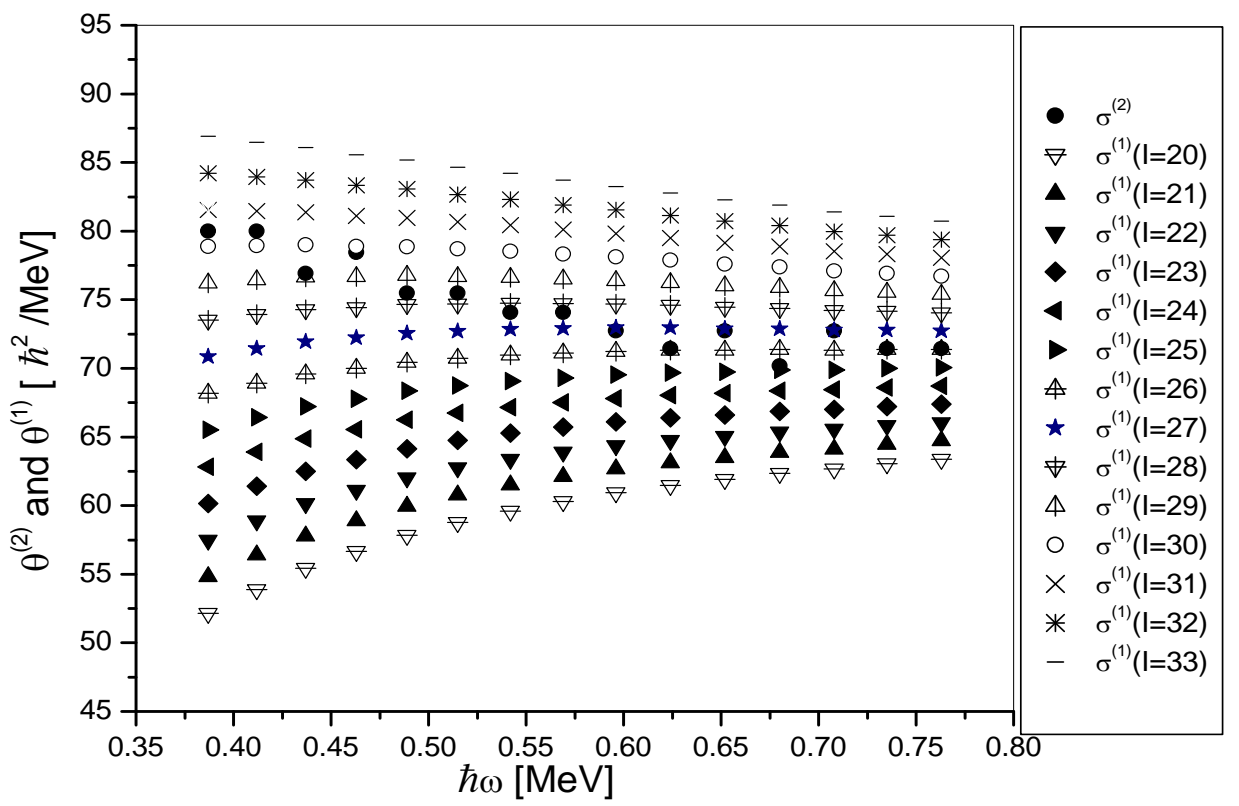

Fig.(6). The same as Fig. (1), but for the SD nucleus ${ }^{148} \mathrm{Eu}(\mathrm{b} 1)$. 


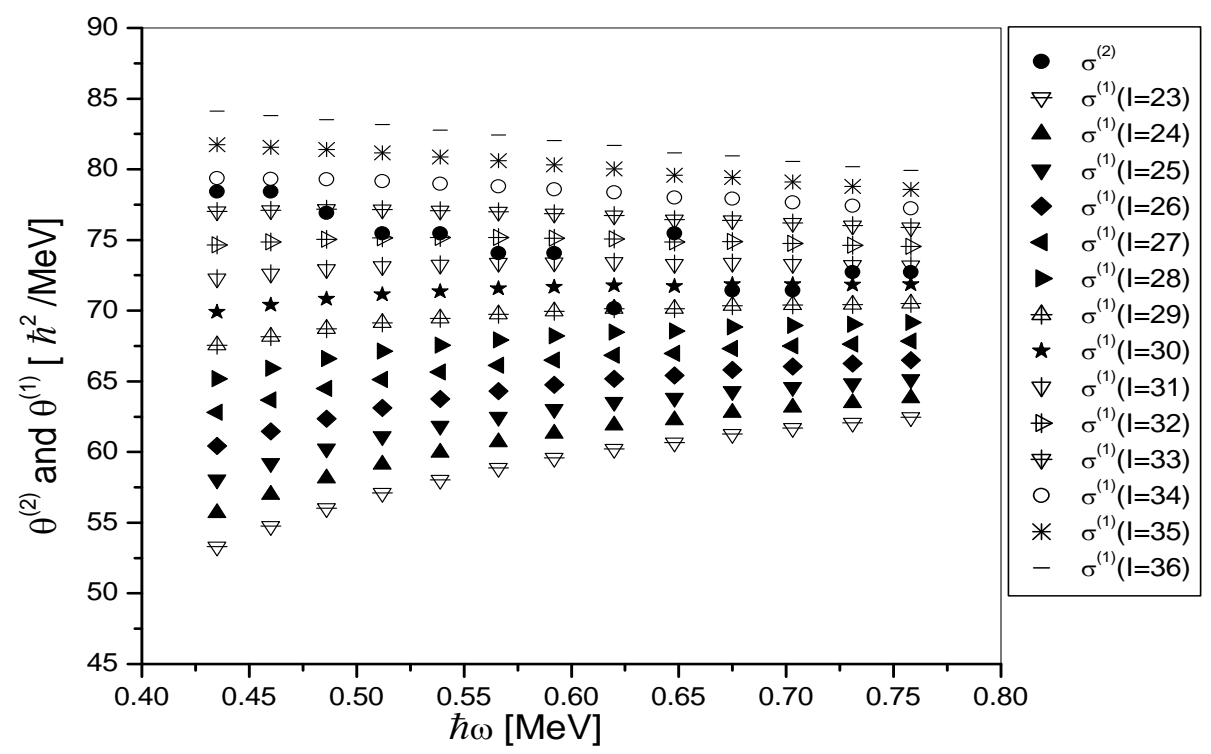

Fig.(7). The same as Fig. (1), but for the SD nucleus ${ }^{148} \mathrm{Eu}(\mathrm{b} 2)$.

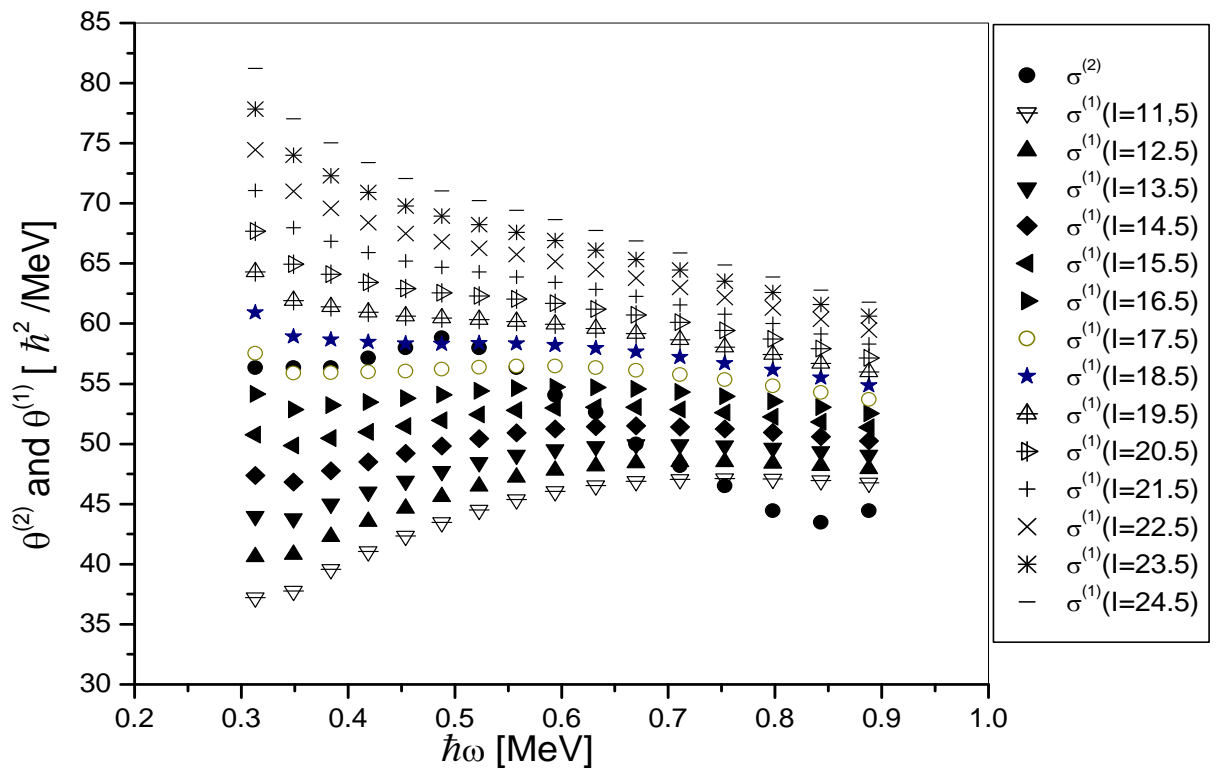

Fig.(8). The same as Fig.(1), but for the for the SD nucleus ${ }^{131} \mathrm{Ce}(\mathrm{b} 1)$. 


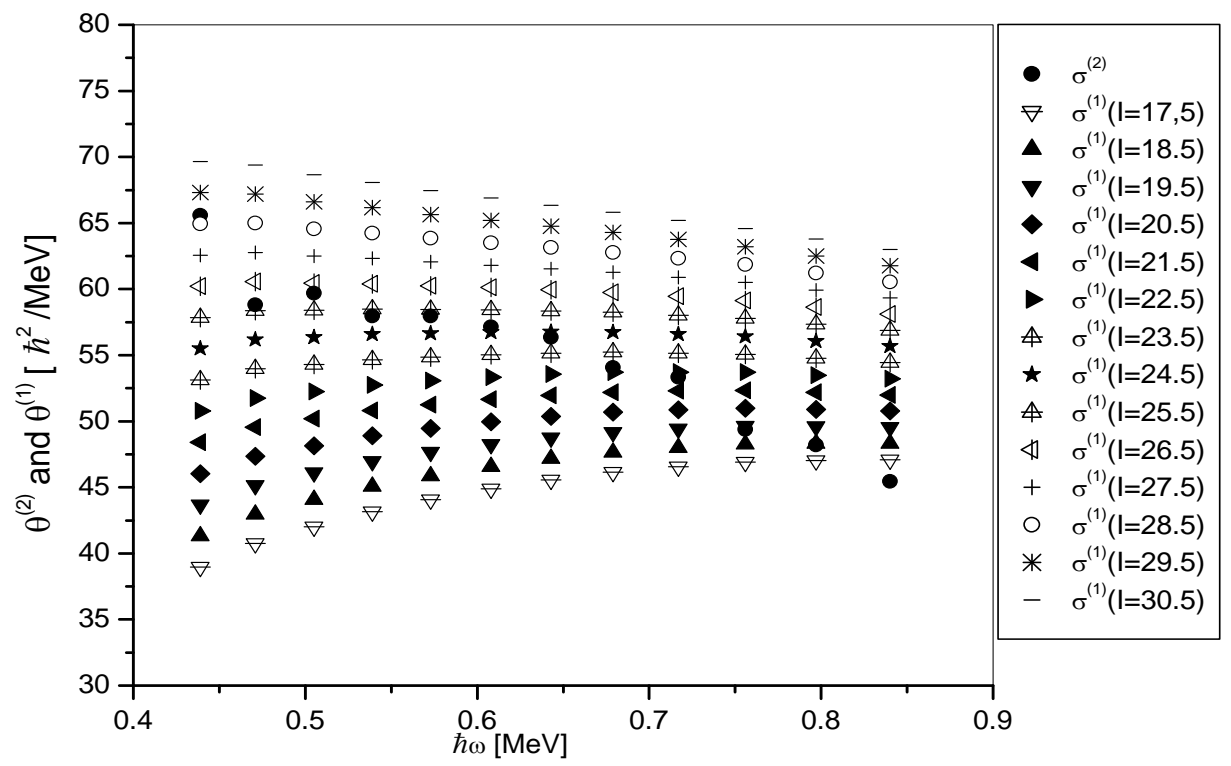

Fig.(9). The same as Fig. (1), but for the SD nucleus ${ }^{131} \mathrm{Ce}(\mathrm{b} 2)$.

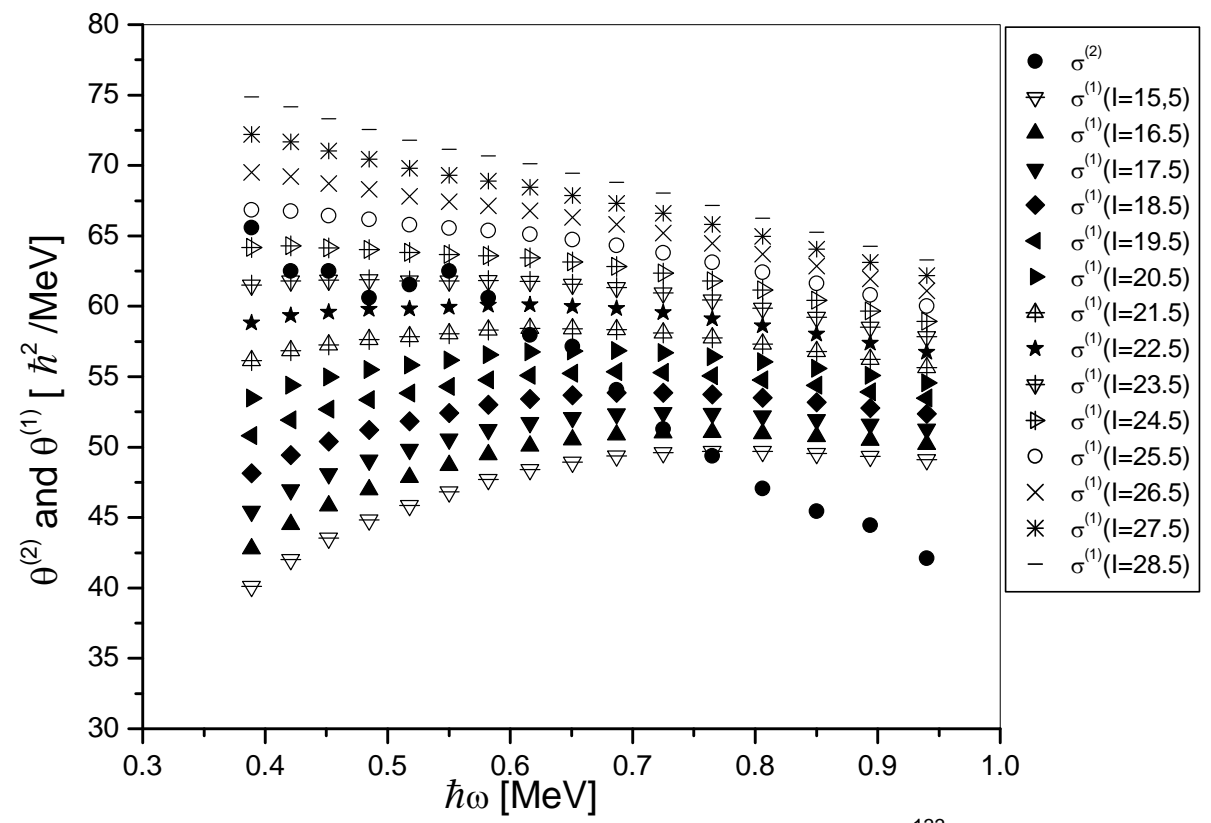

Fig.(10). The same as Fig. (1), but for the SD nucleus ${ }^{133} \mathrm{Ce}(\mathrm{b} 1)$. 


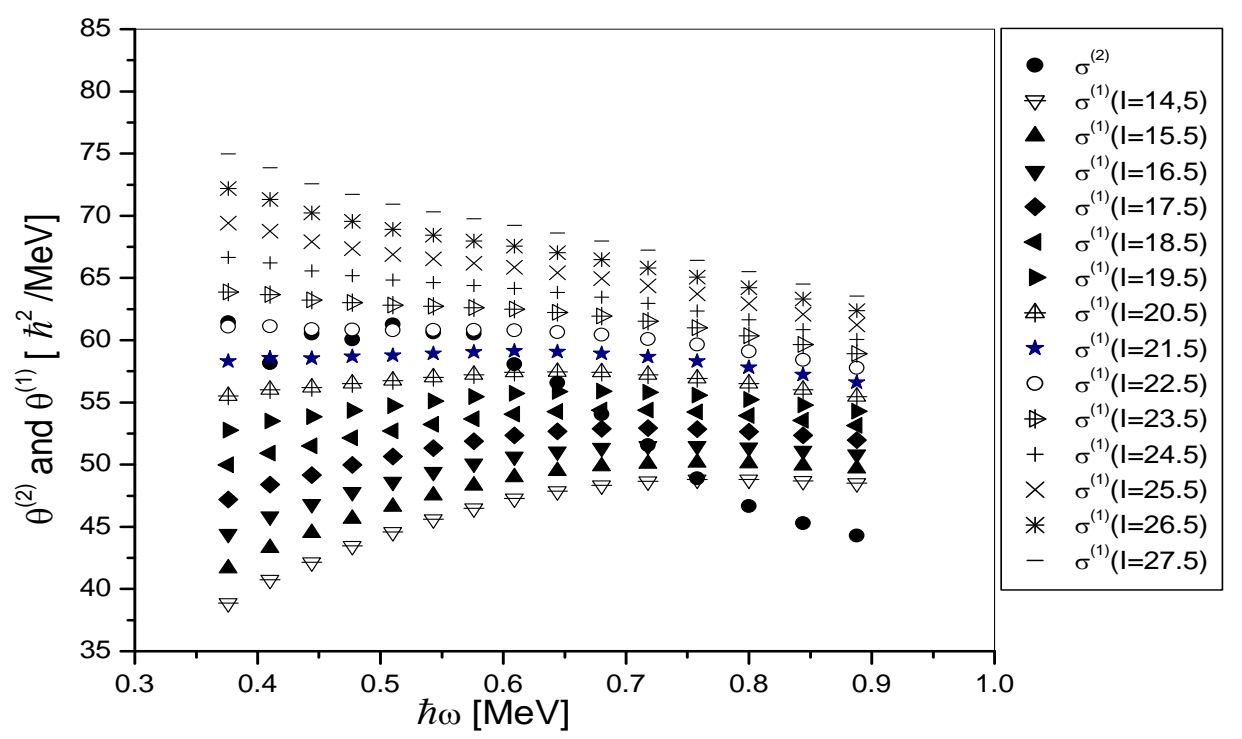

Fig.(11). The same as Fig. (1), but for the SD nucleus ${ }^{133} \mathrm{Ce}(\mathrm{b} 2)$.

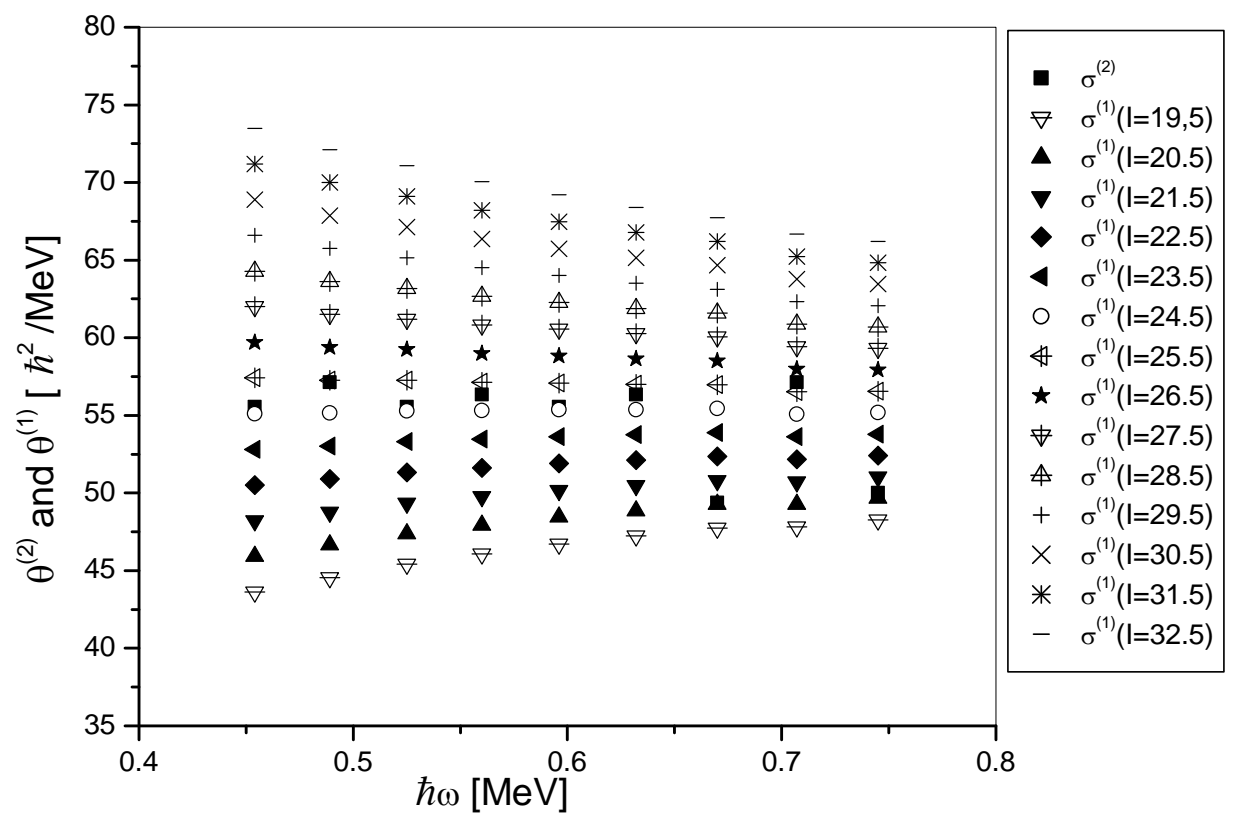

Fig.(12). The same as Fig. (1), but for the SD ucleus ${ }^{133} \operatorname{Pr}(\mathrm{b} 1)$. 


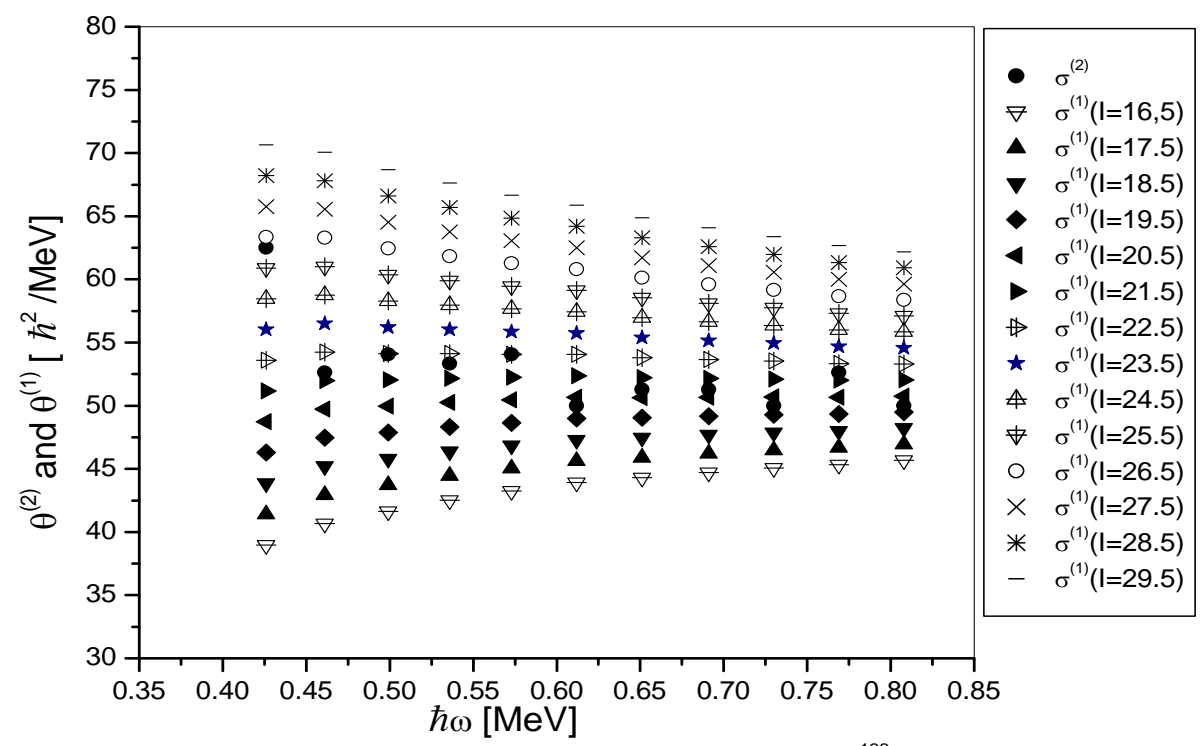

Fig.(13). The same as Fig. (1), but for the SD nucleus ${ }^{133} \operatorname{Pr}(\mathrm{b} 3)$.

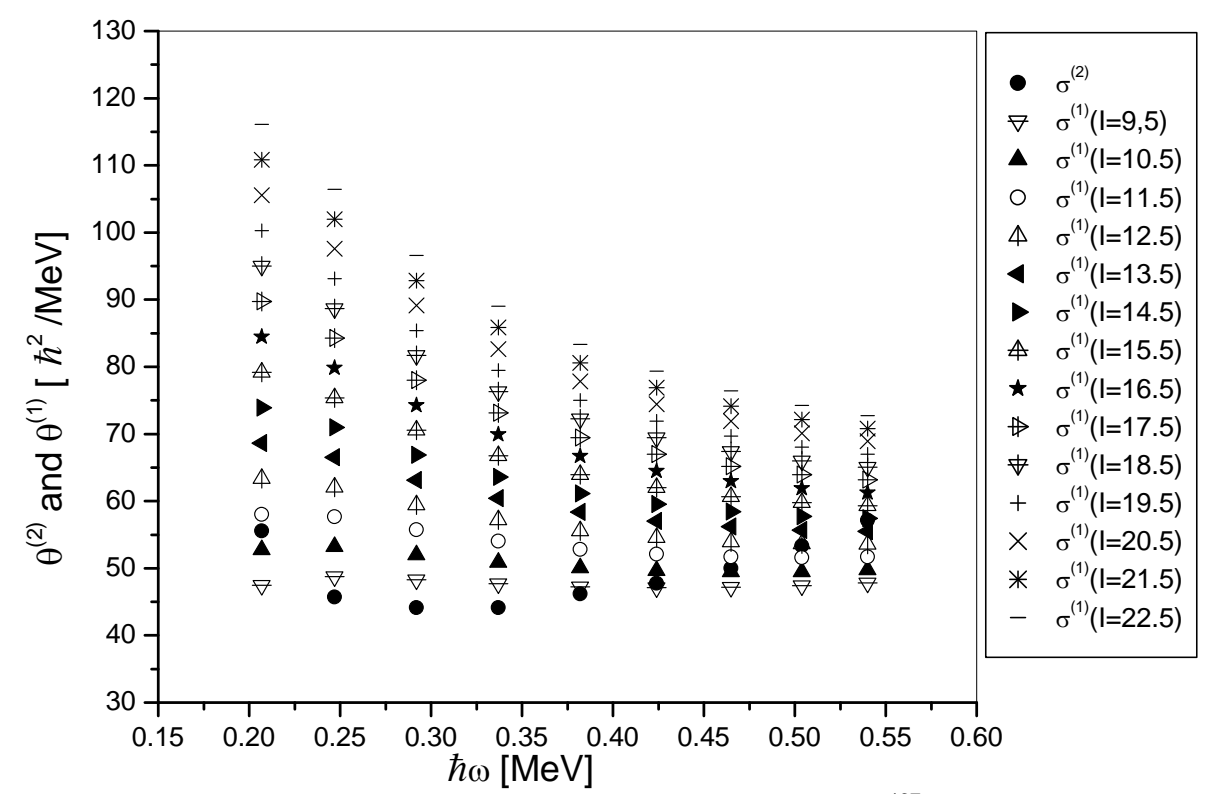

Fig.(14). The same as Fig. (1), but for the SD nucleus ${ }^{137} \mathrm{Sm}(\mathrm{b} 1)$. 


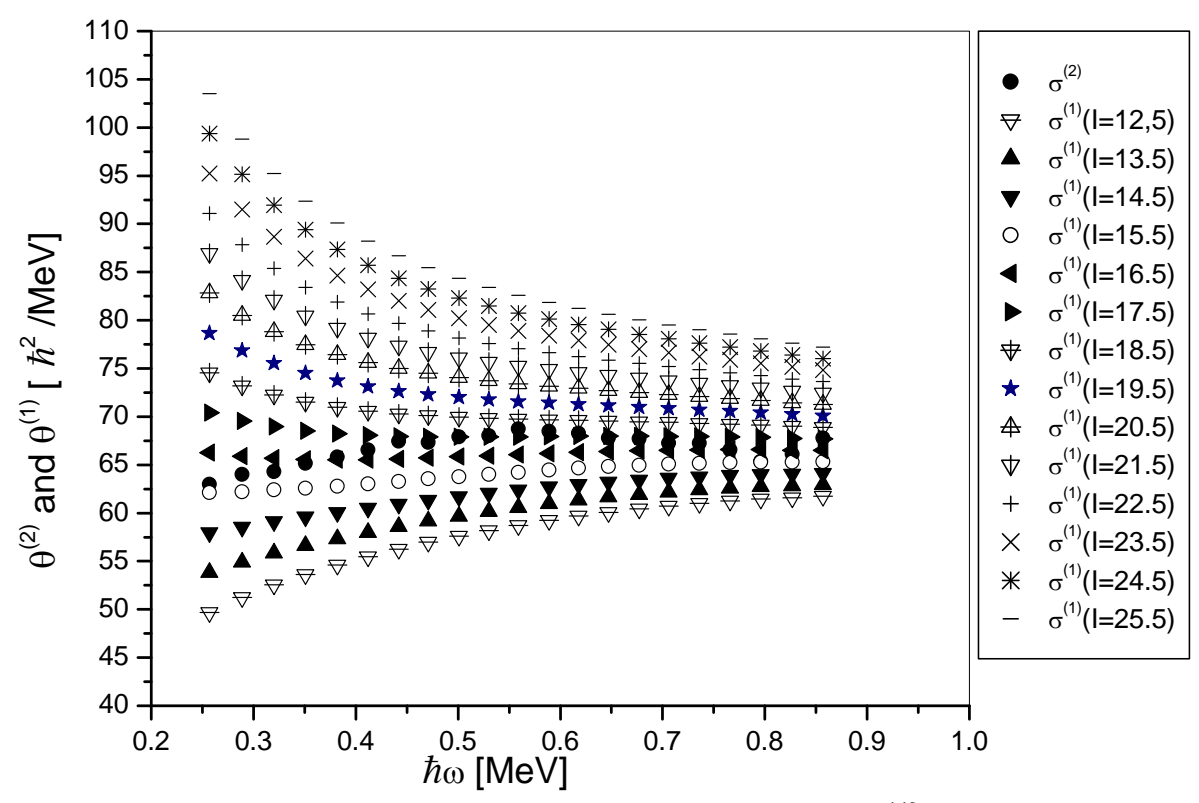

Fig.(15). The same as Fig. (1), but for the SD nucleus ${ }^{143} \mathrm{Eu}(\mathrm{b} 1)$.

The above figures shown that there is a certain spin below which the normal behaviour of the kinematic $\theta^{(1)}$ and dynamic $\theta^{(2)}$ moments of inertia is reversed and the relation between them becomes uncomprehensible. Such certain spin is the socalled lowest spin $I_{f}$ of the superdeformed band which is found to have the same value as " $K$ " for the ground state $\beta$ and $\gamma$-bands. Thus, in the present work, we can take the K-value for the SD band as the value of the assigned lowest spin or the base line spin of that band. The $\gamma$-ray transitions in the 15 SD bands observed in A 100-140 mass region with the aid of the adopted values of " $K$ " was fitted by Eq. (4) and the results are encouraging. The higher order inertial parameters A, B are obtained using the search method [46], to fit the $\gamma$-ray transitions with their experimental ones. This method is succeedingly carried out for the considered fifteen SD bands.

The lowest spin assignments for the fifteen SD bands, the corresponding fitting parameters, the available experimental data [19] and our previous results $[42,43]$ are shown in Table (1). One can easily see from this table that our present results for the band head spin are relatively satisfy their available experimental ones than that obtained in our previous papers [42, 43].

Tables (2-9) illustrate the results for the $\gamma$-ray transitions of the considered fifteen SD bands, where their experimental data (labeled $\operatorname{Exp}^{\mathrm{a}}$ ) are taken from Ref. [19] and their calculated ones (labeled $\mathrm{Cal}^{\mathrm{b}}$ ) are carried out using two fitting parameters (A and B) given in Table (1). " $\sigma$ " is the root mean square deviation value calculated from Eq. (5) [44].

From Tables (2-9), it can be seen that the calculated $\gamma$-ray transition energies E $\gamma$ are in good agreement with their available experimental ones. This ensures that the estimated value of " $K$ " as shown in Figs. (1-15) is to great extent acceptable. Furthermore, the calculated $E \gamma$ values are in abetter agreement with the corresponding experimental data than the corresponding values $[42,43]$. This emphasizes that the present simple approach is more appropriate for describing the rotational spectrum in each SD band in the mass region 100-140 than other approaches $[42,43]$.

The assignments of spin for the considered SD bands make us to calculate and compare the values of the alignment $\mathrm{i}(\omega)$ and the incremental alignments $\Delta \mathrm{i}$ of the IB's [19] exist among the considered SD bands, as shown in Figs. $(16,17)$, respectively. One can easily see from Tables (2-9) that when the difference in the mass number $\Delta \mathrm{A}=0$, as in the case of $\left({ }^{148} \mathrm{Eu}(\mathrm{b} 2)\right.$ vs $\left.{ }^{148} \mathrm{Eu}(\mathrm{b} 1)\right)$, the spin differences $\Delta \mathrm{I}$ in these IB's are just (zero). 
In this case, Figs. $(16,17)$ show that the alignment $\mathrm{i}(\omega)$ and the difference in $\Delta \mathrm{i}$ (incremental alignment) are both around (zero). This emphasizes the fact that the alignment originates only when the difference in mass numbers $\Delta \mathrm{A}$ equals non-zero.

For $\Delta \mathrm{A}=1$, as in the two cases $\left({ }^{133} \mathrm{Ce}(\mathrm{b} 1)\right.$ vs ${ }^{132} \mathrm{Ce}$ (b1)) and $\left({ }^{142} \mathrm{Sm}\right.$ (b1) vs ${ }^{143} \mathrm{Eu}$ (b1)), the spin differences " $\Delta \mathrm{I}$ " are just (1.5) for both two cases where the SD bands $\left\{{ }^{132} \mathrm{Ce}\right.$ (b1) and $\left.{ }^{143} \mathrm{Eu}(\mathrm{b} 1)\right\}$ are assumed as reference bands and $\left\{{ }^{133} \mathrm{Ce}\right.$ (b1) and $\left.{ }^{142} \mathrm{Sm}(\mathrm{b} 1)\right\}$ are assumed as considered bands.

Figure (17) shows that the incremental alignment $\Delta \mathrm{i}$ is around $( \pm 0.2)$ in the first case and ranges from $(-0.1$ to -0.8$)$ in the second case while the spin alignment $i(\omega)$ is around (1.5) in the first case and (one) in the second case, as shown in Fig. (16). Enlarging the mass number as in the case of $\Delta \mathrm{A}=3$, the spin differences $\Delta \mathrm{I}$ in the IB's are just (0.5) in the case of $\left({ }^{131} \mathrm{Ce}(\mathrm{b} 1)\right.$ vs $\left.{ }^{134} \mathrm{Nd}(\mathrm{b} 1)\right)$ where ${ }^{134} \mathrm{Nd}(\mathrm{b} 1)$ is assumed as reference band and ${ }^{131} \mathrm{Ce}(\mathrm{b} 1)$ is assumed as considered band. The incremental alignment $\Delta \mathrm{i}$ as shown in Fig. (17), ranges from $(-0.17$ to 0.03$)$ while the spin alignment $i(\omega)$ is around $(0.5)$ as shown by Fig. (16). These results for the incremental alignment $\Delta \mathrm{i}$ and the alignment $\mathrm{i}(\omega)$ agree the relation: $i(\omega)=\Delta i+\Delta I$ and purvey proof consolidating the consideration of quantized spin alignment in units of $(\hbar / 2)$ [47] previously suggested by Stephens et al. [39, 40]. Moreover, the results of the present investigation for the spin alignments lead to the so-called natural alignments, where odd A- nuclei such as ${ }^{133} \mathrm{Ce}(\mathrm{b} 1)$ and ${ }^{131} \mathrm{Ce}(\mathrm{b} 1)$ have half integer $(1 / 2 \hbar, 3 / 2 \hbar, \ldots .$. alignments while the even A- nucleus ${ }^{142} \mathrm{Sm}(\mathrm{b} 1)$ has integer $\sim(\hbar)$ alignment.

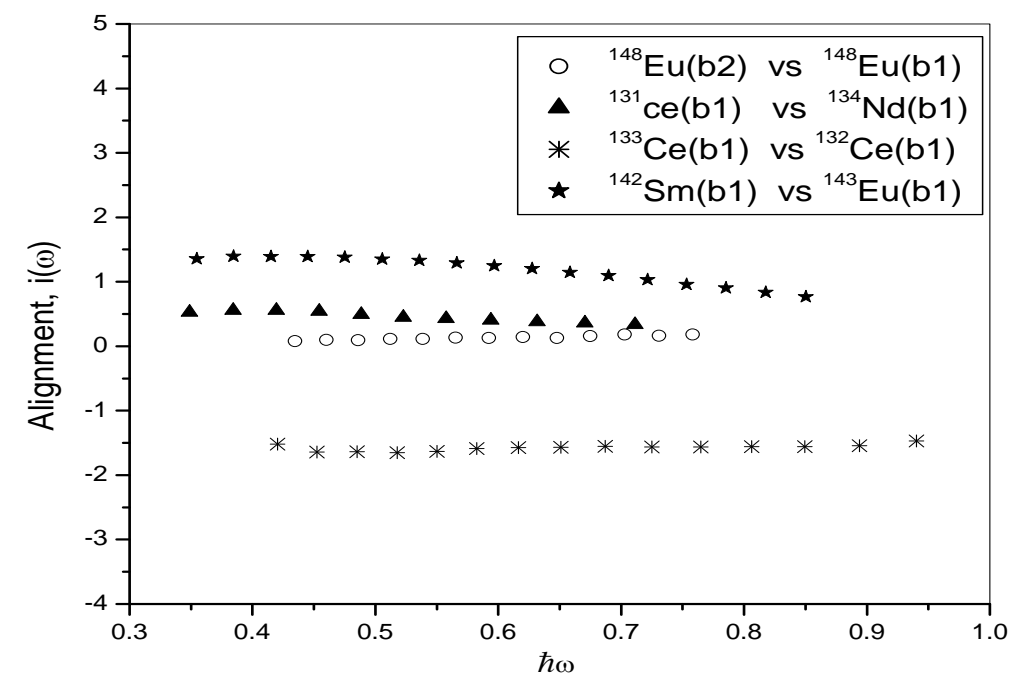

Fig. (16). Spin alignment, $i(\omega)$ as a function of rotational frequency, $\hbar \omega$. 


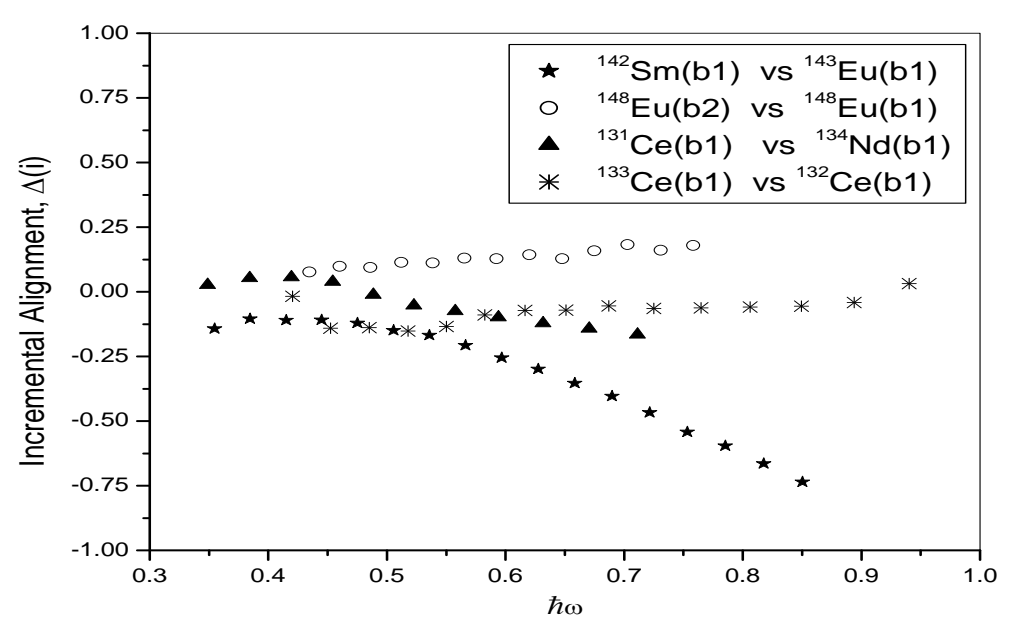

Fig. (17). Incremental alignment, $\Delta(\mathrm{i})$, as a function of rotational frequency.

Table (1): Spin assignments of the fifteen SD bands in the A 100-140 mass region

\begin{tabular}{|c|c|c|c|c|c|c|c|c|}
\hline \multirow[b]{2}{*}{ SD bands } & \multirow[b]{2}{*}{$\begin{array}{c}E_{\gamma}\left(I_{0}+2 \rightarrow I_{0}\right) \\
(\mathbf{K e V})\end{array}$} & \multicolumn{2}{|c|}{ Parameters } & \multirow[b]{2}{*}{$\begin{array}{l}\text { K-value } \\
\text { or } \\
\text { Lowest } \\
\text { spin }\left(I_{f}\right)\end{array}$} & \multicolumn{4}{|c|}{ Calculated band head spin $\left(I_{0}\right)$ and Exp. data } \\
\hline & & $\begin{array}{c}\mathbf{A} \\
(\mathrm{KeV})\end{array}$ & $\mathrm{B} \times 10^{-4}$ & & $\begin{array}{l}\text { Present } \\
\text { work }\end{array}$ & $\begin{array}{c}\text { Previous } \\
\text { works }[42,43]\end{array}$ & $\begin{array}{c}\text { Another } \\
\text { work [19] }\end{array}$ & $\begin{array}{c}\text { Exp.da } \\
\text { ta } \\
{[19]} \\
\end{array}$ \\
\hline${ }^{104} \mathbf{P d}(\mathrm{b} 1)$ & 1263.0 & 12.06 & 9.37 & 22 & 24 & 23,17 & 24 & - \\
\hline${ }^{132} \mathrm{Ce}(\mathrm{b} 1)$ & 808.0 & 6.10 & 2.60 & 29 & 31 & 30, 17 & 19 & - \\
\hline${ }^{134} \mathbf{N d}(\mathbf{b 1})$ & $663.9 \pm 0.5$ & 7.43 & 2.14 & 19 & 21 & 17,15 & 17 & 16 \\
\hline${ }^{136} \mathbf{N d}(\mathbf{b} 2)$ & $888.0 \pm 1.0$ & 6.75 & 2.21 & 29 & 31 & 32,25 & - & 25 \\
\hline${ }^{142} \mathrm{Sm}(\mathrm{b1})$ & 680.0 & 6.49 & 1.18 & 23 & 25 & 24,17 & 25 & - \\
\hline${ }^{148} \mathbf{E u}(\mathbf{b 1})$ & 748.0 & 5.57 & 0.94 & 30 & 32 & 33,22 & 32 & - \\
\hline${ }^{148} \mathbf{E u}(\mathrm{b} 2)$ & 844.0 & 5.61 & 0.87 & 34 & 36 & 37,25 & 28 & - \\
\hline${ }^{131} \mathrm{Ce}(\mathrm{b} 1)$ & 591.0 & 7.26 & 2.95 & $35 / 2$ & $39 / 2$ & $37 / 2,27 / 2$ & $29 / 2$ & - \\
\hline${ }^{131} \mathrm{Ce}(\mathrm{b} 2)$ & 847.0 & 6.66 & 2.41 & $57 / 2$ & $61 / 2$ & $57 / 2,39 / 2$ & $47 / 2$ & - \\
\hline${ }^{133} \mathrm{Ce}(\mathrm{b} 1)$ & 748.0 & 6.40 & 2.39 & $51 / 2$ & $55 / 2$ & $53 / 2,35 / 2$ & $43 / 2$ & - \\
\hline${ }^{133} \mathrm{Ce}(\mathrm{b} 2)$ & 720.3 & 6.92 & 2.23 & $45 / 2$ & $49 / 2$ & $47 / 2,33 / 2$ & $37 / 2$ & - \\
\hline${ }^{133} \operatorname{Pr}(b 1)$ & 871.0 & 7.75 & 1.88 & $49 / 2$ & $53 / 2$ & $49 / 2,43 / 2$ & $55 / 2$ & - \\
\hline${ }^{133} \operatorname{Pr}(\mathbf{b 3})$ & 821.0 & 6.79 & 3.15 & $53 / 2$ & $57 / 2$ & $53 / 2,37 / 2$ & $55 / 2$ & - \\
\hline${ }^{137} \mathbf{S m}(\mathrm{b} 1)$ & 379.0 & 6.43 & 13.02 & $23 / 2$ & $27 / 2$ & $21 / 2,23 / 2$ & $17 / 2$ & \\
\hline${ }^{143} \mathbf{E u}(\mathrm{b} 1)$ & 483.0 & 6.65 & 0.88 & $31 / 2$ & $35 / 2$ & $33 / 2,29 / 2$ & $33 / 2$ & $35 / 2$ \\
\hline
\end{tabular}


Table (2): The transition energies in $\mathrm{Nd}^{134}(\mathrm{b1})$ and $\mathrm{Eu}^{148}(\mathrm{b2})$

\begin{tabular}{|c|c|c|c|c|c|}
\hline & \multicolumn{2}{|c|}{$N d^{134}(b 1)$} & \multicolumn{3}{|c|}{$E u^{148}(b 2)$} \\
\hline & $\mathbf{E}_{\gamma}(\mathbf{I})(\mathrm{KeV})$ & \multirow{2}{*}{$\begin{array}{c}\text { Assigned } \\
\text { I }\end{array}$} & \multicolumn{2}{|c|}{$\mathbf{E}_{\gamma}(\mathbf{I})(\mathbf{K e V})$} & \multirow{2}{*}{$\begin{array}{c}\text { Assigned } \\
\text { I }\end{array}$} \\
\hline & $\operatorname{Exp}^{a^{a}} \quad$ Cal $^{\mathrm{b}}$ & & $\operatorname{Exp}^{\mathbf{a}}$ & $\mathrm{Cal}^{\mathrm{b}}$ & \\
\hline 663.9 & 674.4 & 21 & 844.0 & 843.2 & 36 \\
\hline 736.7 & 738.3 & 23 & 895.0 & 892.7 & 38 \\
\hline 807.8 & 803.2 & 25 & 946.0 & 943.0 & 40 \\
\hline 876.5 & 869.2 & 27 & 998.0 & 994.0 & 42 \\
\hline 942.2 & 936.3 & 29 & 1051.0 & 1045.8 & 44 \\
\hline 1007.4 & 1004.8 & 31 & 1104.0 & 1098.4 & 46 \\
\hline 1074.4 & 1074.5 & 33 & 1158.0 & 1151.9 & 48 \\
\hline 1143.8 & 1145.7 & 35 & 1212.0 & 1206.2 & 50 \\
\hline 1216.0 & 1218.3 & 37 & 1269.0 & 1261.5 & 52 \\
\hline 1289.9 & 1292.6 & 39 & 1322.0 & 1317.8 & 54 \\
\hline 1367.3 & 1368.5 & 41 & 1378.0 & 1375.0 & 56 \\
\hline \multirow[t]{3}{*}{1450.0} & 1446.1 & 43 & 1434.0 & 1433.3 & 58 \\
\hline & & & 1489.0 & 1492.7 & 60 \\
\hline & & & 1544.0 & 1553.2 & 62 \\
\hline \multicolumn{3}{|c|}{$\sigma=7.69 \times 10^{-4}$} & \multicolumn{3}{|c|}{$\sigma=1.59 \times 10^{-3}$} \\
\hline
\end{tabular}

Table (3): The transition energies in $\mathrm{Pd}^{104}(\mathrm{~b} 1)$ and $\mathrm{Nd}^{136}(\mathrm{~b} 2)$

\begin{tabular}{|c|c|c|c|c|c|}
\hline & \multicolumn{2}{|c|}{$\mathbf{P d}^{104}(\mathrm{~b} 1)$} & \multicolumn{3}{|c|}{$\mathrm{Nd}^{136}(\mathrm{~b} 2)$} \\
\hline & \multirow{2}{*}{$\underset{\mathbf{F x n}^{\mathbf{a}}}{\mathbf{E}_{\gamma}(\mathbf{I})(\mathrm{KeV})}$} & \multirow{2}{*}{$\begin{array}{c}\text { Assigned } \\
\text { I }\end{array}$} & \multicolumn{2}{|c|}{$\mathbf{E}_{\gamma}(\mathbf{I})(\mathrm{KeV})$} & \multirow{2}{*}{$\begin{array}{c}\text { Assigned } \\
\text { I }\end{array}$} \\
\hline & & & $\operatorname{Exp}^{\mathbf{a}}$ & Cal $^{\text {b }}$ & \\
\hline 1263.0 & 1262.0 & 24 & 888.0 & 889.5 & 31 \\
\hline 1381.0 & 1382.9 & 26 & 951.0 & 952.4 & 33 \\
\hline 1511.0 & 1508.7 & 28 & 1017.0 & 1016.8 & 35 \\
\hline 1638.0 & 1639.7 & 30 & 1081.0 & 1082.7 & 37 \\
\hline 1763.0 & 1776.5 & 32 & 1151.0 & 1150.3 & 39 \\
\hline 1919.0 & 1919.3 & 34 & 1221.0 & 1219.6 & 41 \\
\hline \multirow[t]{3}{*}{2079.0} & 2068.5 & 36 & 1290.0 & 1290.7 & 43 \\
\hline & & & 1364.0 & 1363.6 & 45 \\
\hline & & & 1438.0 & 1438.6 & 47 \\
\hline \multicolumn{3}{|c|}{$\sigma=1.92 \times 10^{-3}$} & \multicolumn{3}{|c|}{$\sigma=1.32 \times 10^{-4}$} \\
\hline
\end{tabular}


ON THE QUESTION OF SPIN ASSIGNMENT...

\begin{tabular}{|c|c|c|c|c|c|}
\hline \multicolumn{6}{|c|}{ Table (4): The transition energies in $\mathrm{Ce}^{132}(\mathrm{~b} 1)$ and $\mathrm{Sm}^{142}(\mathrm{~b} 1)$} \\
\hline & \multicolumn{2}{|c|}{$\mathrm{Ce}^{132}(\mathrm{~b} 1)$} & \multicolumn{3}{|c|}{$\mathrm{Sm}^{142}(\mathrm{b1})$} \\
\hline & $\underset{\operatorname{Exp}^{\mathbf{E}_{\gamma}(I)}(\mathrm{KeV})}{ }$ Cal $^{\mathbf{b}}$ & $\begin{array}{c}\text { Assigned } \\
\text { I }\end{array}$ & \multicolumn{2}{|c|}{$\mathbf{E}_{\gamma}(\mathbf{I})(\mathrm{KeV})$} & $\begin{array}{c}\text { Assigned } \\
\text { I }\end{array}$ \\
\hline 808.0 & 807.6 & 31 & 680.0 & 692.1 & 25 \\
\hline 864.0 & 866.9 & 33 & 739.0 & 747.3 & 27 \\
\hline 928.0 & 928.0 & 35 & 800.0 & 803.1 & 29 \\
\hline 993.0 & 990.8 & 37 & 860.0 & 859.6 & 31 \\
\hline 1059.0 & 1055.6 & 39 & 920.0 & 916.9 & 33 \\
\hline 1126.0 & 1122.4 & 41 & 981.0 & 975.0 & 35 \\
\hline 1193.0 & 1191.3 & 43 & 1041.0 & 1033.8 & 37 \\
\hline 1262.0 & 1262.5 & 45 & 1102.0 & 1093.6 & 39 \\
\hline 1333.0 & 1335.9 & 47 & 1163.0 & 1154.2 & 41 \\
\hline 1406.0 & 1411.8 & 49 & 1224.0 & 1215.9 & 43 \\
\hline 1484.0 & 1490.2 & 51 & 1286.0 & 1278.5 & 45 \\
\hline 1565.0 & 1571.3 & 53 & 1348.0 & 1342.2 & 47 \\
\hline 1650.0 & 1655.0 & 55 & 1411.0 & 1407.0 & 49 \\
\hline 1739.0 & 1741.6 & 57 & 1475.0 & 1473.0 & 51 \\
\hline 1836.0 & 1831.1 & 59 & 1538.0 & 1540.0 & 53 \\
\hline 1930.0 & 1923.6 & 61 & 1603.0 & 1608.4 & 55 \\
\hline 2030.0 & 2019.2 & 63 & 1668.0 & 1678.0 & 57 \\
\hline & & & 1733.0 & 1749.0 & 59 \\
\hline & $\sigma=1.29 \times 10^{-3}$ & & $\sigma=$ & & \\
\hline
\end{tabular}

Table (5): The transition energies in $\mathrm{Eu}^{148}(\mathrm{~b} 1)$

\begin{tabular}{ccc}
\hline $\begin{array}{c}\left.\mathbf{E}_{\mathbf{\gamma}}(\mathbf{I}) \mathbf{K e V}\right) \\
\mathbf{E x p}^{\mathbf{a}}\end{array}$ & $\mathbf{E u}^{\mathbf{1 4 8}} \mathbf{( b 1 )}$ & $\begin{array}{c}\text { Assigned } \\
\mathbf{I}\end{array}$ \\
\hline 748.0 & 752.5 & 32 \\
798.0 & 801.1 & 34 \\
848.0 & 850.4 & 36 \\
900.0 & 900.3 & 38 \\
951.0 & 951.0 & 40 \\
1004.0 & 1002.4 & 42 \\
1057.0 & 1054.5 & 44 \\
1111.0 & 1107.5 & 46 \\
1165.0 & 1161.4 & 48 \\
1220.0 & 1216.1 & 50 \\
1276.0 & 1271.8 & 52 \\
1331.0 & 1328.5 & 54 \\
1388.0 & 1386.1 & 56 \\
1443.0 & 1444.8 & 58 \\
1499.0 & 1504.5 & 60 \\
1555.0 & 1565.4 & 62 \\
& $\sigma=1.67 \times 10^{-3}$ & \\
\hline
\end{tabular}

Arab J. Nucl. Sci. \& Applic. Vol. 52, No. 3 (2019) 
Table (6): The transition energies in $\mathrm{Ce}^{131}(\mathrm{~b} 1)$ and $\mathrm{Ce}^{133}(\mathrm{~b} 1)$

\begin{tabular}{|c|c|c|c|c|c|}
\hline & \multicolumn{2}{|c|}{$\mathrm{Ce}^{131}(\mathrm{~b} 1)$} & \multicolumn{3}{|c|}{$\mathrm{Ce}^{133}(\mathrm{~b} 1)$} \\
\hline & \multirow{2}{*}{$\underset{\operatorname{Exp}^{\mathrm{a}}}{E_{V}(\mathrm{l})(\mathrm{KeV})}$} & \multirow{2}{*}{$\begin{array}{c}\text { Assigned } \\
\text { I }\end{array}$} & \multicolumn{2}{|c|}{$E_{\gamma}(\mathrm{I})(\mathrm{KeV})$} & \multirow{2}{*}{$\begin{array}{c}\text { Assigned } \\
\text { I }\end{array}$} \\
\hline & & & $\operatorname{Exp}^{a^{a}}$ & $\mathrm{Cal}^{\mathrm{b}}$ & \\
\hline 591.0 & 616.4 & 19.5 & 748.0 & 752.4 & 27.5 \\
\hline 662.0 & 663.9 & 21.5 & 809.0 & 811.4 & 29.5 \\
\hline 733.0 & 728.3 & 23.5 & 873.0 & 871.9 & 31.5 \\
\hline 804.0 & 794.2 & 25.5 & 937.0 & 933.8 & 33.5 \\
\hline 874.0 & 861.5 & 27.5 & 1003.0 & 997.4 & 35.5 \\
\hline 943.0 & 930.4 & 29.5 & 1068.0 & 1062.6 & 37.5 \\
\hline 1011.0 & 1001.1 & 31.5 & 1132.0 & 1129.6 & 39.5 \\
\hline 1080.0 & 1073.6 & 33.5 & 1198.0 & 1198.6 & 41.5 \\
\hline 1151.0 & 1148.1 & 35.5 & 1267.0 & 1269.4 & 43.5 \\
\hline 1225.0 & 1224.7 & 37.5 & 1337.0 & 1342.4 & 45.5 \\
\hline 1301.0 & 1303.4 & 39.5 & 1411.0 & 1417.5 & 47.5 \\
\hline 1381.0 & 1384.4 & 41.5 & 1489.0 & 1494.9 & 49.5 \\
\hline 1464.0 & 1467.8 & 43.5 & 1570.0 & 1574.6 & 51.5 \\
\hline 1550.0 & 1553.7 & 45.5 & 1655.0 & 1656.7 & 53.5 \\
\hline 1640.0 & 1642.3 & 47.5 & 1743.0 & 1741.4 & 55.5 \\
\hline 1732.0 & 1733.6 & 49.5 & 1833.0 & 1828.6 & 57.5 \\
\hline 1822.0 & 1827.8 & 51.5 & 1928.0 & 1918.6 & 59.5 \\
\hline & $\sigma=7.76 \times 10^{-4}$ & & & $1.18 x$ & \\
\hline
\end{tabular}

Table (7): The transition energies in $\operatorname{Pr}^{133}(\mathrm{b1})$ and $\operatorname{Sm}^{137}(\mathrm{b1})$

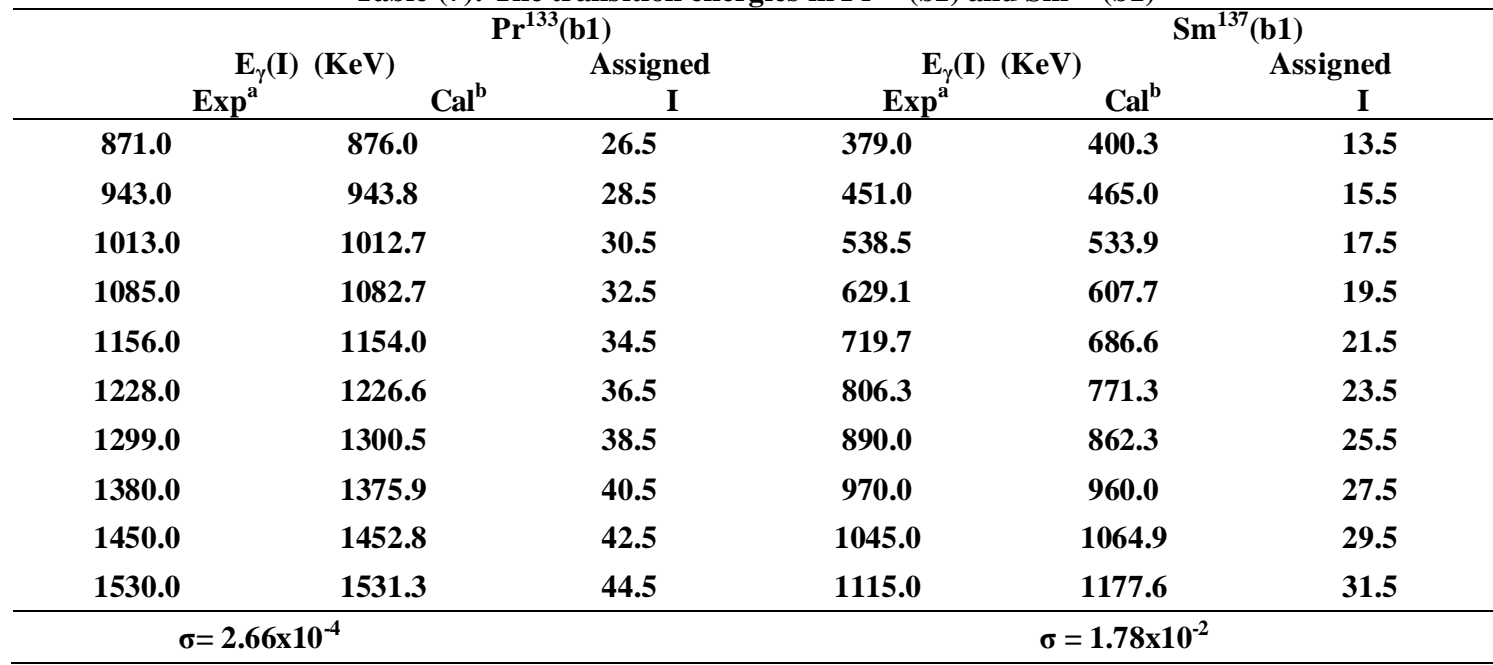


ON THE QUESTION OF SPIN ASSIGNMENT...

\begin{tabular}{|c|c|c|c|c|c|}
\hline \multicolumn{6}{|c|}{ Table (8): The transition energies in $\operatorname{Pr}^{133}(\mathrm{~b} 2)$ and $\mathrm{Ce}^{131}(\mathrm{~b} 2)$} \\
\hline & \multicolumn{2}{|c|}{$\operatorname{Pr}^{133}(\mathbf{b 2})$} & & \multicolumn{2}{|c|}{$\mathrm{Ce}^{131}(\mathrm{b2})$} \\
\hline & \multirow{2}{*}{$\underset{\mathbf{F x p}_{\gamma}^{\mathbf{a}}}{\mathbf{E}_{(}(\mathbf{I})(\mathrm{KeV})}$} & \multirow{2}{*}{$\begin{array}{c}\text { Assigned } \\
\text { I }\end{array}$} & \multicolumn{2}{|c|}{$\mathbf{E}_{\gamma}(\mathbf{I})(\mathrm{KeV})$} & \multirow{2}{*}{$\begin{array}{c}\text { Assigned } \\
\text { I }\end{array}$} \\
\hline & & & $\operatorname{Exp}^{\mathbf{a}^{\prime}}$ & $\mathrm{Cal}^{\mathbf{b}}$ & \\
\hline 821.0 & 829.6 & 28.5 & 847.0 & 849.8 & 30.5 \\
\hline 885.0 & 894.9 & 30.5 & 908.0 & 912.1 & 32.5 \\
\hline 961.0 & 962.1 & 32.5 & 976.0 & 976.0 & 34.5 \\
\hline 1035.0 & 1031.4 & 34.5 & 1043.0 & 1041.6 & 36.5 \\
\hline 1110.0 & 1102.9 & 36.5 & 1112.0 & 1108.8 & 38.5 \\
\hline 1184.0 & 1176.6 & 38.5 & 1181.0 & 1177.9 & 40.5 \\
\hline 1264.0 & 1252.8 & 40.5 & 1251.0 & 1249.0 & 42.5 \\
\hline 1342.0 & 1331.6 & 42.5 & 1322.0 & 1322.0 & 44.5 \\
\hline 1420.0 & 1413.0 & 44.5 & 1396.0 & 1397.1 & 46.5 \\
\hline 1500.0 & 1497.1 & 46.5 & 1471.0 & 1474.5 & 48.5 \\
\hline 1576.0 & 1584.2 & 48.5 & 1552.0 & 1554.1 & 50.5 \\
\hline \multirow[t]{2}{*}{1656.0} & 1674.3 & 50.5 & 1635.0 & 1636.1 & 52.5 \\
\hline & & & 1723.5 & 1720.6 & 54.5 \\
\hline & $\sigma=3.19 \times 10^{-3}$ & & & $=3.83 \times 10$ & \\
\hline
\end{tabular}

Table (9): The transition energies in $\mathrm{Ce}^{133}(\mathrm{~b} 2)$ and $\mathrm{Eu}^{143}(\mathrm{b1})$

\begin{tabular}{|c|c|c|c|c|c|}
\hline & \multicolumn{3}{|c|}{$\mathrm{Ce}^{133}(\mathrm{~b} 2)$} & \multicolumn{2}{|c|}{$\mathrm{Eu}^{143}(\mathrm{~b} 1)$} \\
\hline & $E_{\gamma}(I)(K e V)$ & \multirow{2}{*}{ Assigned } & \multicolumn{2}{|c|}{$E_{\gamma}(\mathrm{I})(\mathrm{KeV})$} & \multirow{2}{*}{$\begin{array}{c}\text { Assigned } \\
\text { I }\end{array}$} \\
\hline & $\operatorname{Exp}^{a} \quad \mathrm{Cal}^{\mathrm{b}}$ & & $\operatorname{Exp}^{a}$ & $\mathrm{Cal}^{\mathrm{b}}$ & \\
\hline 720.3 & 727.3 & 24.5 & 483.0 & 507.2 & 17.5 \\
\hline 785.4 & 788.6 & 26.5 & 546.5 & 561.7 & 19.5 \\
\hline 854.2 & 851.2 & 28.5 & 609.0 & 616.7 & 21.5 \\
\hline 920.3 & 915.0 & 30.5 & 671.2 & 672.0 & 23.5 \\
\hline 986.9 & 980.2 & 32.5 & 732.6 & 727.7 & 25.5 \\
\hline 1052.2 & 1046.8 & 34.5 & 793.4 & 783.9 & 27.5 \\
\hline 1118.2 & 1115.0 & 36.5 & 853.5 & 840.6 & 29.5 \\
\hline 1184.3 & 1184.8 & 38.5 & 912.8 & 897.8 & 31.5 \\
\hline 1253.2 & 1256.4 & 40.5 & 972.2 & 955.6 & 33.5 \\
\hline 1323.9 & 1329.6 & 42.5 & 1031.1 & 1013.9 & 35.5 \\
\hline 1397.9 & 1404.9 & 44.5 & 1089.9 & 1072.9 & 37.5 \\
\hline 1475.5 & 1482.1 & 46.5 & 1148.1 & 1132.5 & 39.5 \\
\hline 1557.3 & 1561.3 & 48.5 & 1206.5 & 1192.9 & 41.5 \\
\hline 1643.0 & 1642.7 & 50.5 & 1265.5 & 1253.9 & 43.5 \\
\hline 1731.3 & 1726.3 & 52.5 & 1324.1 & 1315.7 & 45.5 \\
\hline \multirow[t]{8}{*}{1821.6} & 1812.2 & 54.5 & 1383.2 & 1378.4 & 47.5 \\
\hline & & & 1442.7 & 1441.8 & 49.5 \\
\hline & & & 1502.2 & 1506.1 & 51.5 \\
\hline & & & 1562.3 & 1571.3 & 53.5 \\
\hline & & & 1623.5 & 1637.4 & 55.5 \\
\hline & & & 1684.0 & 1704.5 & 57.5 \\
\hline & & & 1743.0 & 1772.6 & 59.5 \\
\hline & \multicolumn{2}{|l|}{$\sigma=1.29 \times 10^{-3}$} & & $=3.62 \times 1$ & \\
\hline
\end{tabular}




\section{Conclusion}

Using the present direct method, lowest spins $\left(\mathrm{I}_{\mathrm{f}}\right)$, band head spins $\left(\mathrm{I}_{0}\right)$, and $\mathrm{K}$-values of 15 SD bands in the A 100-140 mass region were assigned. This was carried out by studying the dependence of the kinematic $\theta^{(1)}$ and dynamic $\theta^{(2)}$ moments of inertia on the rotational frequency $\hbar \omega$. Most of the calculated $\gamma$-ray transition energies are in a good agreement with their corresponding experimental ones rather than that obtained before with other approaches $[42,43]$. The good results obtained here for the spins and $\gamma$-ray transition energies $\mathrm{E}_{\gamma}$ indicate that the expansion parameters (A and B) are well determined and the direct method employed here is more suitable to use than others. For the identical bands IB's (twin bands) that exist among the considered SD bands, the alignments for most of these identical SD bands tend to be quantized in units of $(1 / 2) \hbar$ or $\hbar$ [40]. The agreement between the lowest spin and the assumption of quantized alignment in unit of $(\hbar / 2)$ emphasizes the superiority of using the present direct approach than others. The alignment (i) for $\Delta \mathrm{A}=0$ also emphasizes the suitability of using this direct method in representing the 100-140 mass region.

\section{References}

1-P.J. Twin et al., Phys. Rev. Lett. 57, 811 (1986).

2-E.F. Moore et al., Phys. Rev. Lett. 63, 360 (1989).

3-B. Singh, R.B. Firestone and S.Y.F. Chu, Nucl. Data Sheets 78, 1 (1996).

4-Xiao-Ling Han, Cheng-Li Wu and Cheng-Li, Atomic data and nuclear data tables 63, 117 (1996).

5-F. Cristancho et al., Phys. Lett. B 357, 280 (1995).

6-H.Q. Jin et al., Phys. Rev. Lett. 75, 1471 (1995).

7-C.E. Svensson et al., Phys. Rev. Lett. 79, 1233 (1997); Phys. Rev. Lett. 82, 3400 (1999).

8-A. O. Macchiavelli, J. Burde and R. M. Diamond, Phys. Rev. C38, 1088 (1988).

9-K. Tanab and K. Sugawara, Phys. Lett. B259, 12 (1991).

10-B. Kharraja and U. Garg, Phys. Rev. Lett. 80, 1845 (1998).

11-M. J. Godfrey, Y. He and I. Jenkins, J. Phys. G15, L163 (1989).

12-G. Hackman et al., Phys. Rev. C47, R433 (1993).

13-A. Atac et al., Acta Phys. Pol. B24, 395 (1993).

14-F. Camera, Yad. Fiz. 64, No. 6, 1114 (2001); Phys. Atomic nuclei 64, 1039

15-F. Camera et al., Acta Phys. Pol. B32, 807 (2001).

16-Y.-X. liu, J.-J. Wang and Q.-Z. Han, Phys. Rev. C64, 064320 (2001).

17-S. Leoni et al., Phys. Lett. B498, 137 (2001).

18-Yu Khazov, I. Mitropolsky and A. Rodionov, Nuclear Data Sheets 107, 2715-2930 (2006).

19-B. Singh, R. Zywina and R.B. Firestone, Nuclear Data Sheets, 97, 241 (2002).
20-NNDC (National Nuclear Data Center), Bookhaven National Laboratory, [cited on June 2002] [Down-loaded from http:/www.nndc.bnl.gov/chart/]

21-J.E. Draper et al., Phys. Rev. C42, R1791 (1990); ibid 42, R179 (1991).

22-F.S. Stephens et al., Nucl. Phys. A520, 91c (1990).

23-J.A. Becker et al., Nucl. Phys. A520, 187c (1990) ; Phys. Rev. C41, R9, (1990); Phys. Rev. C46, 889 (1992).

24-J.Y. Zeng et al., Phys. Rev. C44, R745 (1991).

25-R. Piepenbring and K.V. Protasov, Z. Phys. A345, 7 (1993).

26-F. Xu and J. Hu, Phys. Rev. C49, 1449 (1994).

27-J.Y. Zeng et al., Commun. Theor. Phys. 24, 125 (1995).

28-A.M. Hegazi, M.H. Ghoniem and A.M. Khalaf, Egypt. J. Phys. 30, No. 3, 293 (1999).

29-A.M. Khalaf, M. Allam and M.H. Ghoniem, Egypt. J. Phys. 33, No. 1, 67 (2002).

30-A.M. Khalaf, Egypt. J. Phys. 33, No. 3, 585 (2002).

31-A.S. Shalaby, Commun. Theor. Phys. (Beijing, China) 41, 454-460 (2004).

32-A.S. Shalaby, Egypt. J. Phys. 36, No. 1, 85 (2005).

33-S.M. Harris, Phys. Rev. Lett. 13, 663 (1964); ibid. Phys. Rev. B138, 509 (1965).

34-S.A. Abd El-Ghany, Egypt. J. Phys. 34, No. 3, 347 (2003).

35-S.A. Abd El-Ghany, Egypt. J. Phys. 36, No. 1, 35 (2005).

36-A.S. Shalaby, Acta Physica Hungarica A, Vol.25, no. 1, 117-134 (2006).

37-P.J. Twin, Workshop on the Nucleus at High Spin, Niles Bohr Institute, Copenhagen, Denmark, Oct. 2-27, 1989, T. Byrski et al., Phys. Rev. Lett.64, 1650 (1990).

38-W. Nazarewicz, P.J. Twin, P. Fallon and J.D. Garrett, Phys. Rev. Lett. 64, 1654 (1990).

39-F.S. Stephens et al., Phys. Rev. Lett. 64, 2623 (1990).

40-F.S. Stephens et al., Phys. Rev. Lett. 65, 301 (1990).

41-H.R. Andrews, D. Ward, R.L. Graham and J.S. Geiger, Nucl. Phys. A219, 141 (1974).

42-A.S. Shalaby et al., Non-linear phenomena in complex systems, V.15, no.1, 1-22 (2012).

43-A.S. Shalaby, International Journal of Physical Science, V.9, no.7, 154- 173 (2014)

44-Alpana Goel, Uma V. Sasidharan Nair and Archana Yadav, Open Physics (formerly Cent. Eur. J. Phys.), Vol. 12, no. 9, 683-700 (2014)

45-C.S. Wu, J.Y. Zeng, Z. Xing, X.Q. Meng, , Phys. Rev. C45, 261 (1992)

46-Numerical Recipes in Fortran, edited by W.H. Press, B.P. Flannery, S.A. Teukolsky and W.T. Vetterling (Cambridge University, Second edition, 1992, p.683).

47-J.Y. Zeng et al., Phys. Rev. C44, R1745 (1991). 